\title{
InTelligent Adviser Module: Proposals AND AdaPtive Learning CAPABILITIES
}

\author{
Damir Haskovic, Branko Katalinic, Ilija Zec, \\ Ilya Kukushkin \& Alina Zavrazhina
}
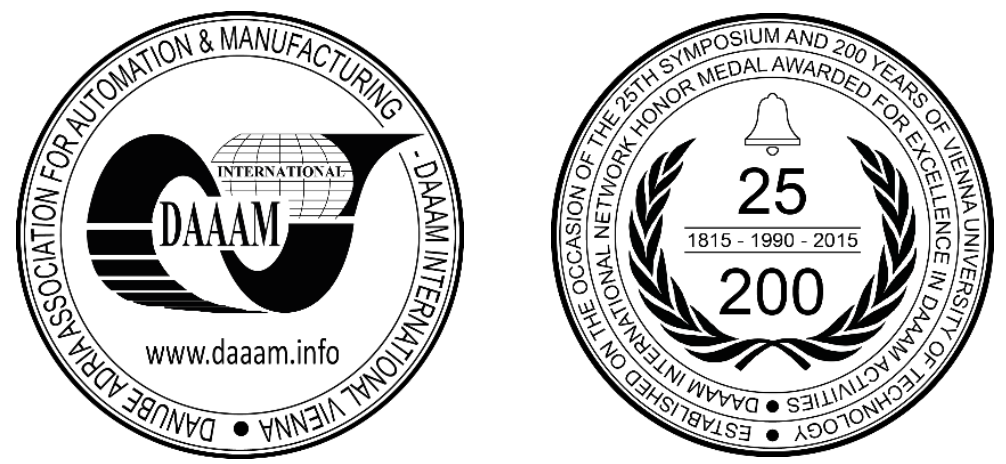

This Publication has to be referred as: Haskovic, D[amir]; Katalinic, B[ranko]; Zec, I[lija]; Kukushkin, I[lya] \& Zavrazhina, A[lina] (2017). Intelligent Adviser Module: Proposals and Adaptive Learning Capabilities, Proceedings of the 28th DAAAM International Symposium, pp.1191-1196, B. Katalinic (Ed.), Published by DAAAM International, ISBN 978-3-902734-11-2, ISSN 1726-9679, Vienna, Austria

DOI: $10.2507 / 28$ th.daaam.proceedings. 165

\begin{abstract}
This paper presents the Intelligent Adviser Module (IAM) as a decision support tool for the system operator in Bionic Assembly System (BAS). Here, the system operator is the main human decision maker. To achieve high work efficiency of BAS, he needs to make high quality decisions in limited time and with incomplete information about the actual system state and its components. This time shortage and fragmented information brings stress to the system operator and forces him to make lower quality decisions. In such situations he uses the proposals from the IAM where he can accept, reject or inspect them. These proposals are based on many parameters and also on the digitally recorded data from all shop floor elements. The IAM collects this data and from it produces new system specific knowledge. The accuracy of IAM proposals heavily depends on the validity and usability of such acquired data. A new algorithm is developed and described which enables the IAM to collect, index and verify new data through adaptive learning. As a result, any new shop floor element behaviour can be compensated. This demonstrates the adaptive nature of the IAM as an integral part of the BAS control structure.
\end{abstract}

Keywords: Intelligent Adviser Module; Bionic Assembly System; hybrid control structure; proposals; adaptive learning

\section{Introduction}

Current product development has introduced new challenges for modern assembly systems. These include increased product complexity and variety as well as a shorter product lifetime [1]. As an answer, a Bionic Assembly System (BAS) concept based on task distribution, intelligence and self-organization was introduced [2].

BAS represents a next generation of hybrid assembly systems [3]. It is a part of a natural development within Industry 4.0 [4] [13]. BAS is a complex production system. Here, the human system operator is the main decision maker [5]. To achieve functionality and high work efficiency, the system operator must be able to make high quality decisions in limited time with fragmented and incomplete information about the actual system states and its components. 
Quality of decisions and time needed to reach them by the system operator are variable, due to his human nature (concentration, stress, fatigue and other) [6] [7] [12]. Because of this, the quality of decisions can be lower, and the time needed to reach them can be longer than objectively possible. To improve that, the Intelligent Manufacturing Systems (IMS) group from Vienna University of Technology has introduced a decision support tool for the system operator. This tool is named as the Intelligent Adviser Module (IAM). As an integral part of BAS control system, the IAM should take into consideration actual system states, past system states, external data from manuals and other documentation, human experts and past system behaviour [8].

All BAS shop floor elements (assembly stations, mobile robots, shop floor operators) produce digital data which is recorded. One of the advantages of the IAM is its ability to use this recorded data to produce and accumulate new system specific knowledge [14]. This makes it possible for the quality of IAM proposals to constantly improve. When the IAM gives more precise proposals, the system operator can make better quality decisions in shorter time and avoid or minimise lost machine time [9].

However, it can oftentimes happen that the individual shop floor elements are replaced with new ones. When a new shop floor element is introduced, the main issue is, how does the IAM compensate for the potential new element behaviour? In other words, how to be sure that the used, already accumulated knowledge is up to date and useful? This is very important because if the IAM is using inadequate or obsolete knowledge, the proposals could be incorrect and cause even more serious problems.

Therefore, the main aim of this paper is to develop an algorithm which enables the IAM to collect, index and verify new data through adaptive learning. As a result, any new shop floor element behaviour can be compensated. The paper starts by describing the main digitally recorded BAS data stream as well as the position of the IAM in contrast to the BAS control structure. Middle part of the paper describes types of IAM proposals and their use by the system operator. The paper concludes with the presented IAM adaptive learning algorithm.

\section{BAS data stream}

During his shift in BAS, the system operator needs to constantly reach decisions. These decisions are based on fragmented and incomplete information about the actual system states and its components. On one side, the main source of information is based on his communication with other human workers and on the other side, from the audio / visual feedback as shown in Fig. 1.

The main digitally recorded data stream in BAS represents a vast collection of data. It is formed between the control and the controlled systems. This includes all the commands, responses and status messages.

It is impractical and moreover, impossible for the system operator to completely utilize all this data. For this reason, only a small part of this data stream is actively presented to the system operator in real time. The main purpose of this data selection is to give data about actual system states at the system operator's disposal. In order for the IAM to give relevant and useful information to the system operator, the target and the actual state of the system are constantly monitored.

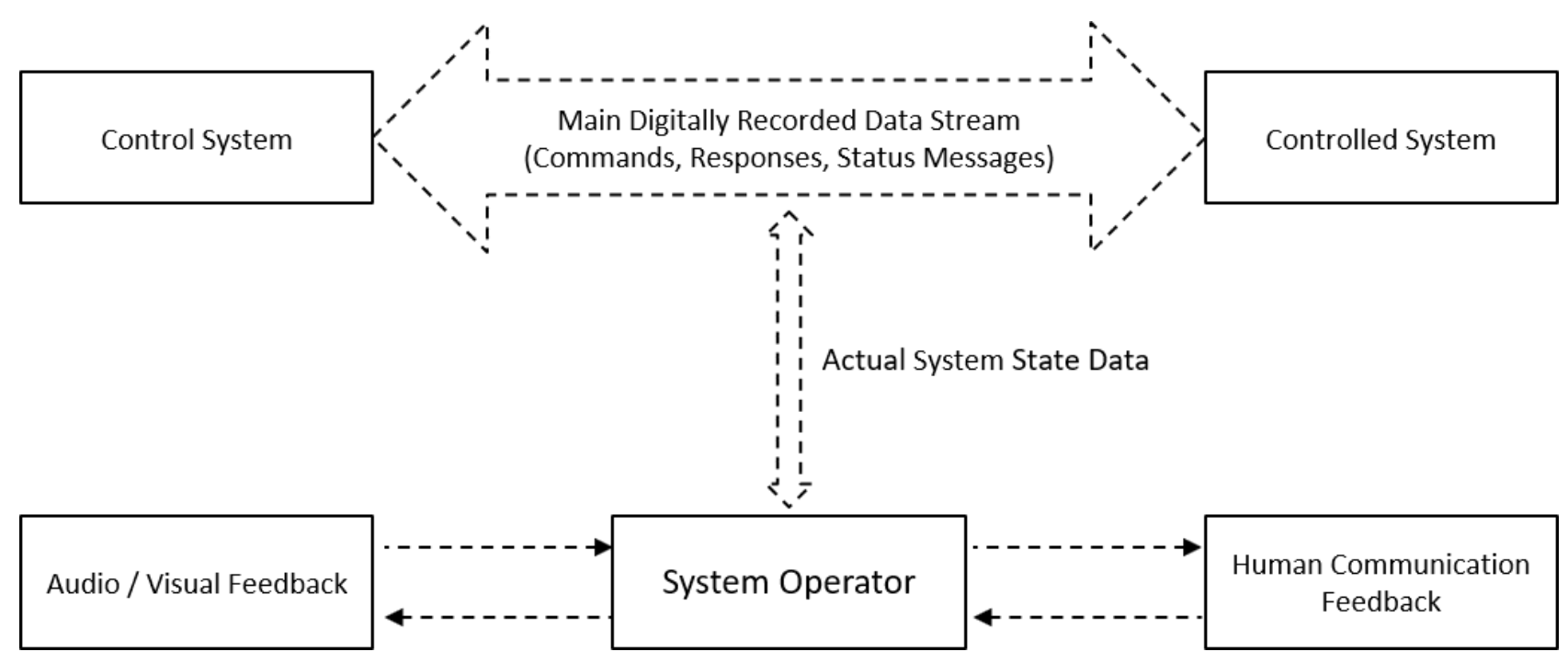

Fig. 1. Main sources of information for the system operator

As started the IAM is an integral part of the BAS control structure. The primary rule is that the IAM must not interfere with the operation of the BAS control system or have any direct influence on it. Therefore, the IAM needs to be implemented exclusively as a data collection system. That means that the data stream has a single direction (read-only) from the BAS control system to the IAM as shown in Fig. 2. 


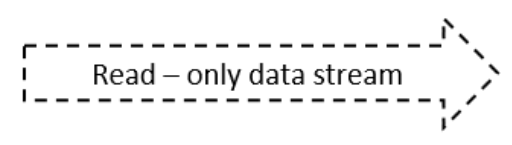

Intelligent Adviser Module

Fig. 2. IAM - Read only access to BAS control system

Otherwise, if the IAM would have the ability to send data directly to the control system, it would stop being a decision support system. and become a decision-making system [10]. This is not the goal of IAM in the context of BAS as a human centric system. On the other side, bidirectional exchange of information (data) takes place between the system operator and the IAM. Here, the system operator can receive feedback information in form of graphs, tables, data and of course, proposals.

\section{Types of proposals and their use by the system operator}

For the system operator, the most useful outputs from the IAM are proposals. He can use them in various scenarios. Based on problem complexity, information accuracy and knowledge amount, there are two principle types of proposals which can be defined:

- Implicit proposals - If a problem is very complex, or there is insufficient data or the IAM Knowledge Base does not contain any applicable knowledge, the IAM outputs implicit proposals. These can be in form of an overview, statistics, comparisons, etc. The main goal of such proposals is to give an inspiration or an idea to the system operator in which case they can be more generalized and open to interpretation (For example: the battery health of MR1 is at $93 \%$ which is higher when compared to the battery health of MR2 which is $15 \%$ ). This information does not specify what the problem might be exactly, but it might be useful to the system operator to come closer to a solution.

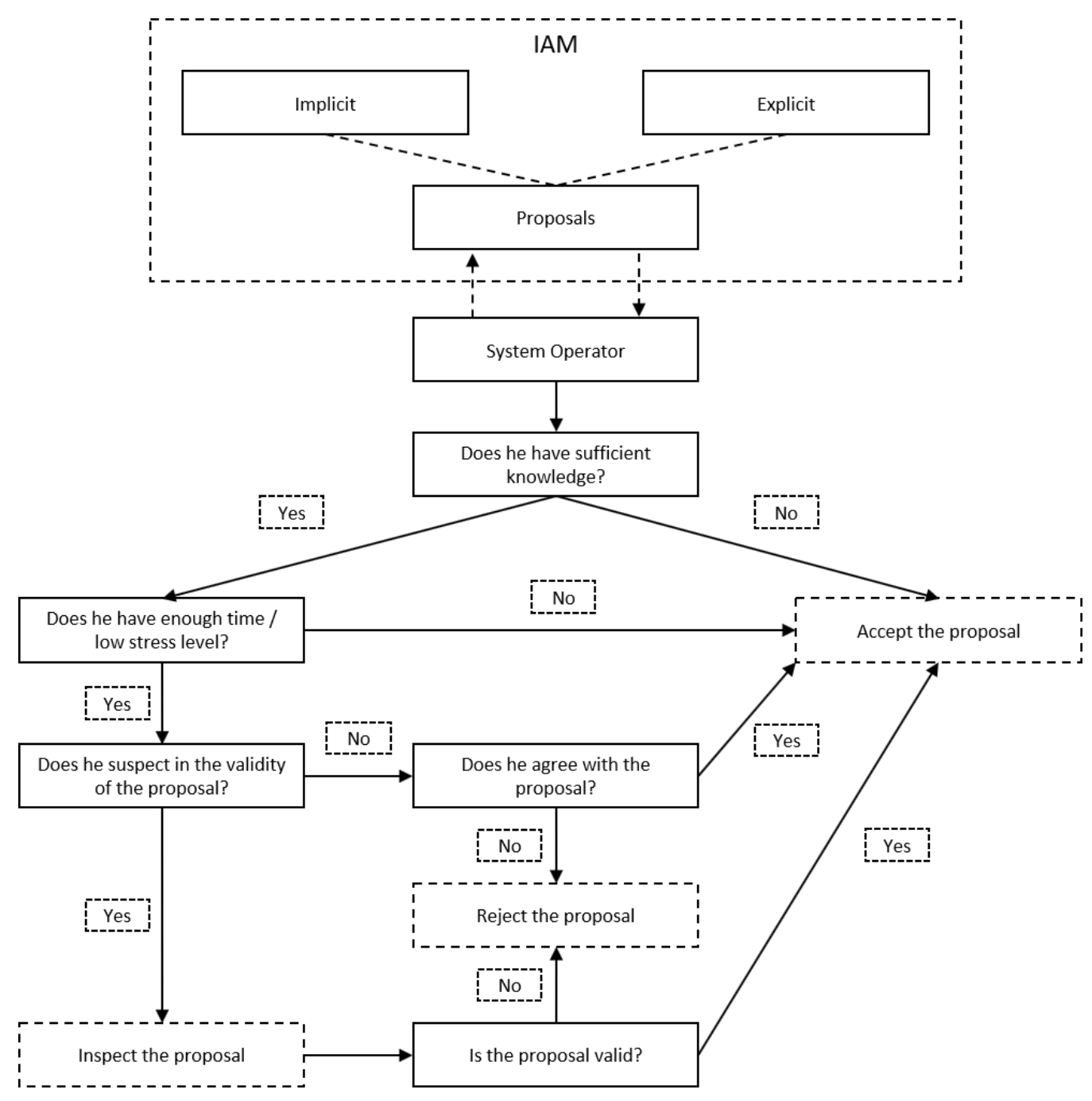

Fig. 3. Types of proposals and their use by the system operator 
- Explicit proposals - these proposals are a result of the IAM's applicable Knowledge Base and sufficient information. In this case, the IAM is able to specify what the problem is and how to resolve it. As a result, the system operator is given explicit proposals. These can be in form of necessary steps, precise descriptions or problem definitions. The main goal of such proposals is to free the system operator from active contemplating in cases where he does not have the time, knowledge or will.

Fig. 3. shows the position of the system operator in contrast to proposals. In principle, he can accept, reject or inspect the validity of proposals. Which action he will choose, depends on the situation context and other certain factors. When the system operator is faced with a new problem, the first factor which comes in play is does he have sufficient level of knowledge to recognize and solve it. If no, he does not have any choice but to accept the proposal.

If yes, then the context of the situation plays a vital role. In other words, is he exposed to low stress levels or does he have enough time to contemplate about a decision. If no, he does not have any choice but to accept the proposal. If yes, does he suspect in the validity of the proposal. If no, does he agree with the proposal. If he has the knowledge, time and agrees with the proposal, then naturally he accepts it. On the other hand, if he does not agree, he will reject it.

If the system operator suspects the validity of the proposal, that means that he has sufficient knowledge and time to inspect the proposal. According to the inspection, if the proposal is valid it is accepted and if it is not valid, it is rejected.

\section{IAM Adaptive learning}

BAS shop floor elements represent a set of comparable hardware and personnel. This includes same or at the very least, similar mobile robots and assembly stations as well as similarly trained shop floor operators. During the execution of BAS working scenarios, these elements can be performing similar tasks respective to their function. Additionally, during their simultaneous operations they can have similar performance and statuses.

During their operational lifetime in BAS, these elements produce digital data which is recorded. This data is used to produce and accumulate new knowledge. However, hardware can be replaced with new type of machines, each shop floor operator can have individual work habits or methods etc.

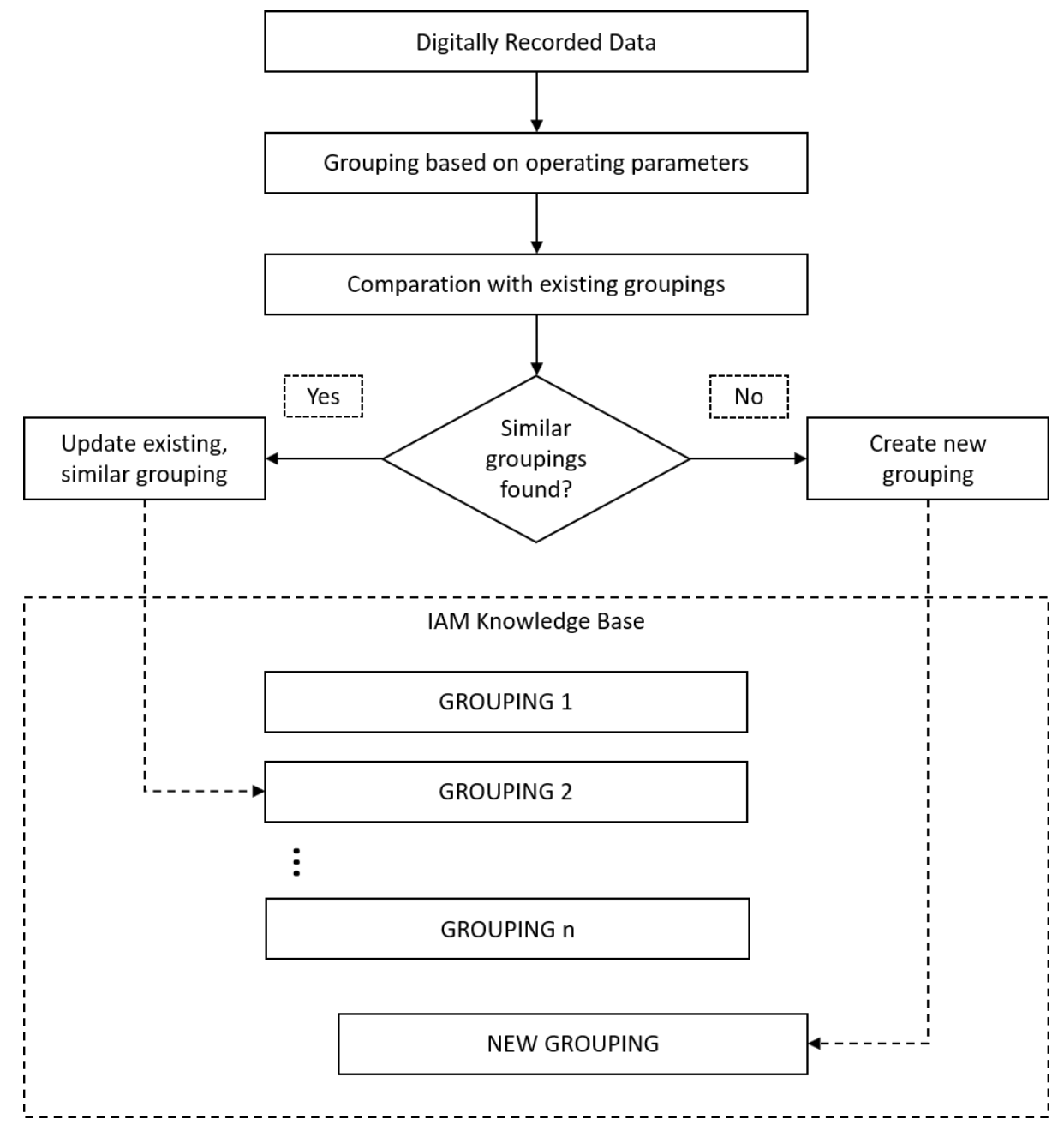

Fig. 4. Intelligent Adviser Module Adaptive Learning Algorithm 
The issue here is - from where does the new knowledge accumulation begin? When a new shop floor element is introduced how does the IAM compensate for the potential new element behaviour? In other words, how to be sure that the used, already accumulated knowledge is up to date and useful? This is very important because if the IAM is using inadequate knowledge the proposals could be wrong and cause even more serious problems.

In order to avoid this, all new sources of knowledge have to be documented, indexed and verified through adaptive learning as shown in Fig. 4. IAM's adaptive learning algorithm automatically forms groupings from digitally recorded data. These groupings are based on similar operating parameters from individual shop floor elements and their working conditions. All groupings are contained and organized within the IAM Knowledge Base.

This algorithm continuously compares the newly created input data with existing groupings and tries to find the most similar grouping to that input. This search can have the following two results:

- Similar grouping found. The element which produced this input data will be associated with the performance of the identified grouping. That means its behaviour is within specified tolerances and previous knowledge can be applied. Any possible, minor differences between this input data and the grouping are used to update the grouping.

- Similar grouping not found. It means that the element which produced this data is operating in a new manner and previous knowledge should not be applied. When this happens, this input data becomes a base for a new grouping. When there are enough of such out-of-bound inputs it means a new behaviour is emerging from that specific shop floor element. This defines the adaptive nature of the IAM where its accumulated knowledge base can be used even when elements are changing [11].

However, one issue would still need to be resolved - determination of the Behaviour Tolerance Line (BHL). BHL specifies the tolerance or the amount of allowed differences between these compared shop floor parameters. The key is to find a balanced BHL.

If the BHL is set too low, even the slightest differences between the data inputs would classify as "out of bound". As a result, there could be a large number of newly formed groupings when in fact there would not be that many new behaviour characteristics for a specific shop floor element. This would unnecessarily increase data consumption as well as processing resources.

On the other hand, if the BHL is set too high, the crucial differences between data inputs would not be registered. That means there would be a small number of groupings and any protentional new shop floor element behaviour would not be detected. As a consequence, the IAM proposals could be less accurate.

\section{Conclusion}

A new algorithm for the IAM adaptive learning was proposed and developed. Initial results show that the inclusion of such a learning algorithm could further improve the IAM as a decision support tool for the system operator. Adaptive learning allows to collect, index and verify digitally recorded data which is generated by all shop floor elements in BAS. Such validated data is used to forms groupings based on similarly operating parameters. These groupings describe the different behaviours of the shop floor elements. This allows the IAM to compensate if a new element is added or the already existing ones are operating differently. As a result, new system specific knowledge is produced and accumulated. This knowledge is a basis for more accurate IAM proposals. Accurate proposals allow the system operator to make better quality decisions in shorter time and to avoid or minimise lost machine time in BAS. Without adaptive learning, proposals would be based on data which is not applicable and would even worsen an emergency situation during the execution of working scenarios. The limitation of this research is that the development and the implementation phases are separated. This means that without access to real world dynamic data, results cannot be verified. Future research will focus on methods for determining the Behaviour Tolerance Line (BTL). Additionally, next step includes experiments with laboratory generated data in order to confirm the applicability of the proposed adaptive learning algorithm for the IAM.

\section{Acknowledgments}

This paper would not be possible without the mentorship and encouragement from Univ. Prof. Dr.sc. Dr.mult.h.c. Prof.h.c. Branko Katalinic.

\section{References}

[1] Ming, X. G., Yan, J. Q., Lu, W. F., \& Ma, D. Z. (2005). Technology solutions for collaborative product lifecycle management-status review and future trend. Concurrent Engineering, 13(4), 311-319

[2] Katalinic, B., Kukushkin, I., Pryanichnikov, V., \& Haskovic, D. (2014). Cloud Communication Concept for Bionic Assembly System, Procedia Engineering, Volume 69, 2014, Pages 1562-1568, ISSN 1877-7058, doi:10.1016/j.proeng.2014.03.156 
[3] Katalinic, B., Kukushkin, I. K., Cesarec, P., \& Kettler, R. (2012). Hybrid control structure and scheduling of bionic assembly system. In Proc. 8th International Conference of DAAAM Baltic, Industrial Engineering (pp. 483-489). Tallinn, Estonia

[4] Post, P. (2014). "Smart Systems for Intelligent Manufacturing - Industry 4.0" Plenary Lecture, 25th DAAAM International Symposium, Vienna, Austria

[5] Haskovic, D., Katalinic, B. \& Kukushkin, I. (2015). Role of the Adviser Module in the Hybrid Assembly Subordinating Control Structure, Procedia Engineering, Volume 100, 2015, Pages 1706-1713, ISSN 1877-7058, http://dx.doi.org/10.1016/j.proeng.2015.01.546

[6] Getty, David J., et al. (1995). System operator response to warnings of danger: A laboratory investigation of the effects of the predictive value of a warning on human response time, Journal of Experimental Psychology: Applied 1.1 (1995): 19

[7] Brake, D. J., \& Bates, G. P. (2001). Fatigue in industrial workers under thermal stress on extended shift lengths. Occupational Medicine, 51(7), 456-463

[8] Haskovic, D., Katalinic, B., Kildibekov, A. \& Kukushkin, I. (2016). Intelligent Adviser Module for Bionic Assembly Control System: Functions and Structure Concept, Proceedings of the 26th DAAAM International Symposium, pp.1158-1165, B. Katalinic (Ed.), Published by DAAAM International, ISBN 978-3-902734-07-5, ISSN 1726-9679, Vienna, Austria

[9] Haskovic, D., Katalinic, B., Zec, I., Kukushkin, I. \& Zavrazhina, A. (2016). Structure and Working Modes of the Intelligent Adviser Module, Proceedings of the 27th DAAAM International Symposium, pp.0866-0875, B. Katalinic (Ed.), Published by DAAAM International, ISBN 978-3-902734-08-2, ISSN 1726-9679, Vienna, Austria, DOI: 10.2507/27th.daaam.proceedings. 125

[10] Aronson, J. E., Liang, T. P., \& Turban, E. (2005). Decision support systems and intelligent systems. Pearson Prentice-Hall

[11] Lee, J., Kao, H. A., \& Yang, S. (2014). Service innovation and smart analytics for industry 4.0 and big data environment. Procedia Cirp, 16, 3-8

[12] Shumsky, A.; Zhirabok, A. \& Kalinina, N. (2017). Human-Operator Behaviour Monitoring in IT-Systems, Proceedings of the 28th DAAAM International Symposium, pp.0160-0167, B. Katalinic (Ed.), Published by DAAAM International, ISBN 978-3-902734-11-2, ISSN 1726-9679, Vienna, Austria, DOI: 10.2507/28th.daaam.proceedings.021

[13] Nikolic, B.; Ignjatic, J.; Suzic, N.; Stevanov, B. \& Rikalovic, A. (2017). Predictive Manufacturing Systems in Industry 4.0: Trends, Benefits and Challenges, Proceedings of the 28th DAAAM International Symposium, pp.07960802, B. Katalinic (Ed.), Published by DAAAM International, ISBN 978-3-902734-11-2, ISSN 1726-9679, Vienna, Austria, DOI: 10.2507/28th.daaam.proceedings.112

[14] Achsan, H. T.; Suhartanto, H. S. \& Wibowo, W. C. (2017). Ontology Enrichment for Multi-Domain Knowledge and Expertise Representation, Proceedings of the 28th DAAAM International Symposium, pp.1170-1177, B. Katalinic (Ed.), Published by DAAAM International, ISBN 978-3-902734-11-2, ISSN 1726-9679, Vienna, Austria, DOI: 10.2507/28th.daaam.proceedings. 162 